\title{
Optimization-based Design of Crude Oil Distillation Units using Rigorous Simulation Models
}

DOI:

10.1021/acs.iecr.7b01014

\section{Document Version}

Accepted author manuscript

Link to publication record in Manchester Research Explorer

\section{Citation for published version (APA):}

Ibrahim, D., Jobson, M., \& Guillén-Gosálbez, G. (2017). Optimization-based Design of Crude Oil Distillation Units using Rigorous Simulation Models. Industrial and Engineering Chemistry Research, 56(23).

https://doi.org/10.1021/acs.iecr.7b01014

\section{Published in:}

Industrial and Engineering Chemistry Research

\section{Citing this paper}

Please note that where the full-text provided on Manchester Research Explorer is the Author Accepted Manuscript or Proof version this may differ from the final Published version. If citing, it is advised that you check and use the publisher's definitive version.

\section{General rights}

Copyright and moral rights for the publications made accessible in the Research Explorer are retained by the authors and/or other copyright owners and it is a condition of accessing publications that users recognise and abide by the legal requirements associated with these rights.

\section{Takedown policy}

If you believe that this document breaches copyright please refer to the University of Manchester's Takedown Procedures [http://man.ac.uk/04Y6Bo] or contact uml.scholarlycommunications@manchester.ac.uk providing relevant details, so we can investigate your claim.

\section{OPEN ACCESS}




\section{Optimization-based Design of Crude Oil Distillation Units using Rigorous Simulation Models}

Dauda Ibrahim, Megan Jobson, and GONZALO GUILLEN GOSALBEZ

Ind. Eng. Chem. Res., Just Accepted Manuscript • Publication Date (Web): 18 May 2017

Downloaded from http://pubs.acs.org on May 24, 2017

\section{Just Accepted}

"Just Accepted" manuscripts have been peer-reviewed and accepted for publication. They are posted online prior to technical editing, formatting for publication and author proofing. The American Chemical Society provides "Just Accepted" as a free service to the research community to expedite the dissemination of scientific material as soon as possible after acceptance. "Just Accepted" manuscripts appear in full in PDF format accompanied by an HTML abstract. "Just Accepted" manuscripts have been fully peer reviewed, but should not be considered the official version of record. They are accessible to all readers and citable by the Digital Object Identifier (DOI®). "Just Accepted" is an optional service offered to authors. Therefore, the "Just Accepted" Web site may not include all articles that will be published in the journal. After a manuscript is technically edited and formatted, it will be removed from the "Just Accepted" Web site and published as an ASAP article. Note that technical editing may introduce minor changes to the manuscript text and/or graphics which could affect content, and all legal disclaimers and ethical guidelines that apply to the journal pertain. ACS cannot be held responsible for errors or consequences arising from the use of information contained in these "Just Accepted" manuscripts. 


\title{
Optimization-based Design of Crude Oil Distillation Units using Rigorous Simulation Models
}

\author{
Dauda Ibrahim ${ }^{1, *}$, Megan Jobson ${ }^{1}$, Gonzalo Guillén-Gosálbez ${ }^{2}$ \\ 1 Centre for Process Integration, School of Chemical Engineering and Analytical \\ Science, University of Manchester, Manchester M13 9PL, UK \\ 2 Department of Chemical Engineering, Centre for Process Systems Engineering, \\ Imperial College, South Kensington Campus, London SW7 2AZ, UK
}

\begin{abstract}
The complex nature of crude oil distillation units, including their interactions with the associated heat recovery network and the large number of degrees of freedom, makes their optimization a very challenging task. We address here the design of a complex crude oil distillation unit by integrating rigorous tray-by-tray column simulation using commercial process simulation software with an optimization algorithm. While several approaches were proposed to tackle this problem, most of them relied on simplified models that are unable to deal with the whole complexity of the problem. The design problem is herein formulated to consider both structural variables (the number of trays in each column section) and operational variables (feed inlet temperature, pump-around duties and temperature drops, stripping steam flow rates and reflux ratio). A simulation-optimization approach for designing such a complex system is applied, which searches for the best design while accounting for heat recovery opportunities using pinch analysis. The approach is illustrated by its application to a specific distillation unit, in which numerical results demonstrate that the new approach is capable of identifying appealing design options while accounting for industrially relevant constraints.
\end{abstract}

Keywords: Process design, heat integration, genetic algorithm, grand composite curve 


\section{Introduction}

Crude oil distillation is one of the most complex and energy-intensive separation units in the petroleum refining industry. The crude oil distillation system comprises a complex distillation unit and a heat recovery network in which the crude oil feed is partially vaporised. Figure 1 illustrates a typical petroleum refinery crude oil distillation system. The system includes a fired heater that typically consumes fuel equivalent to 1 to $2 \%$ of the oil being processed ${ }^{1,2}$. This combustion of fuel is associated with high $\mathrm{CO}_{2}$ emissions and high operating costs. Extensive heat recovery is routinely implemented in crude oil distillation systems to reduce energy costs.

In grassroots design, several degrees of freedom related to the column structure, its operating conditions and the associated heat recovery network are subject to optimization. The need to account for the complex interactions between these subsystems makes the design of crude oil distillation columns a highly challenging task. For a new ('grassroots') design, the column configuration (number of trays in each section of the column and location of the feed tray, pump-arounds and side-stripper draws) and the operating conditions (feed inlet temperature, pump-around duties and temperature drops, stripping steam flow rates and reflux ratios) need to be selected. In addition, the heat recovery network (known as the preheat train) needs to be designed simultaneously. In this way, the column can be designed to create heat recovery opportunities that can be further exploited by the heat exchanger network. The design of this heat recovery network aims to identify the network configuration and heat transfer area that minimise the total annualised cost while accounting for both capital and operation expenditures. 


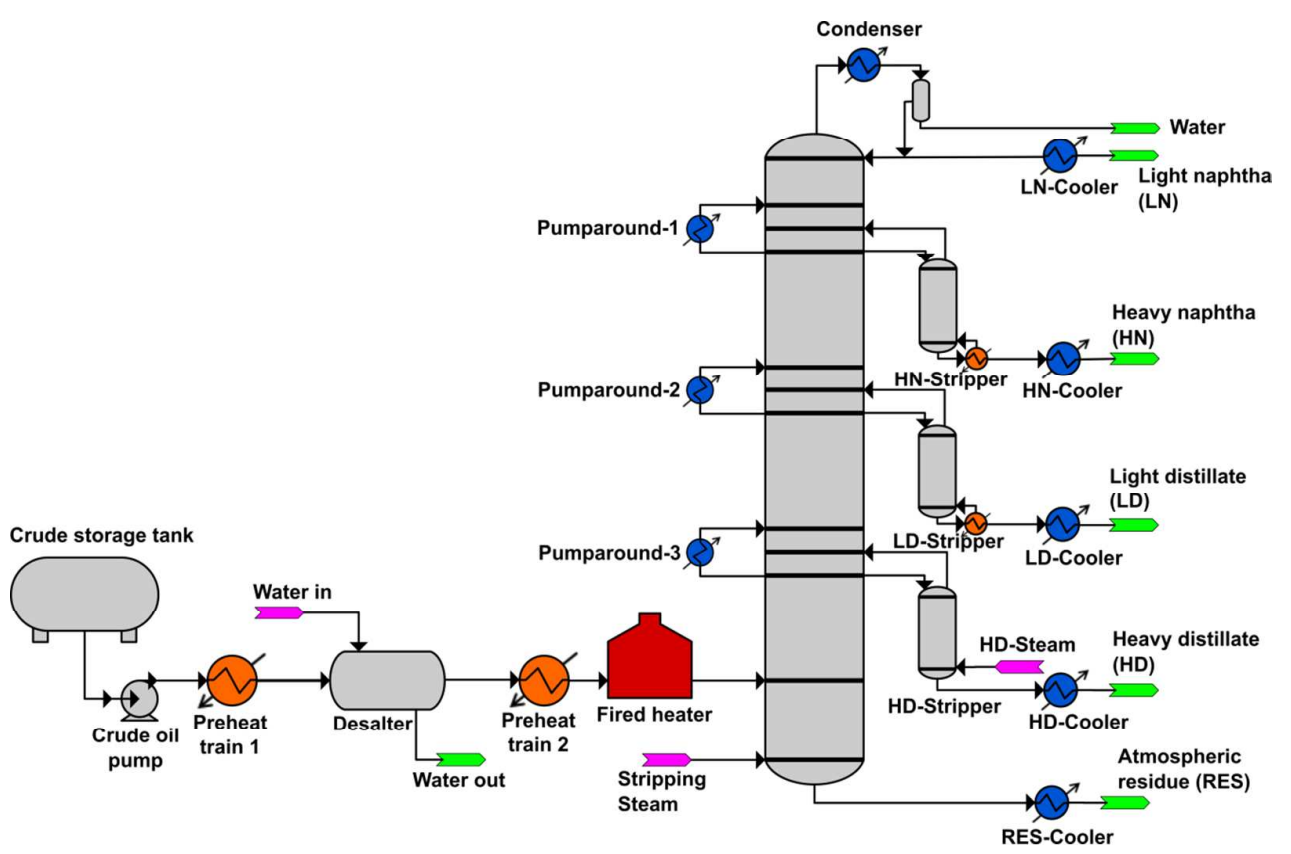

Figure 1 Typical crude oil distillation system

The operation of a standard crude oil distillation column is as follows (see Figure 1). Stored raw crude oil is partially heated in Preheat Train 1 and fed to a desalter, which removes dissolved or suspended salts from the crude oil $\mathrm{feed}^{3}$. The crude oil is further heated, in Preheat Train 2 and a fired heater, before being fed to the atmospheric distillation column. The preheat trains use heat recovered from the crude distillation unit, particularly the pumparounds, condenser and product streams. The partially vaporised crude oil is fed to the atmospheric distillation column a few trays above the bottom stage. Stripping steam is supplied to the column at the bottom stage, which partly suppresses the boiling point of the crude mixture and further vaporises the crude oil mixture. The crude oil is separated into various fractions, such as light naphtha $(\mathrm{LN})$, heavy naphtha $(\mathrm{HN})$, light distillate (LD) and heavy distillate (HD). Side-strippers remove light components from side-draws using stripping steam or reboilers. Pump-arounds provide internal reflux and create heat recovery opportunities by cooling and returning liquid streams withdrawn from the column. The residue from the atmospheric column contains valuable hydrocarbons, which are typically further separated in a vacuum distillation column (not shown in Figure 1).

Conventional design methods ${ }^{4-6}$ consider the complex column and the heat recovery network in separate steps, without taking into account interactions between the two subsystems. 
Various researchers ${ }^{7-9}$ have applied optimization techniques to design the crude oil distillation column while simultaneously accounting for the heat recovery network. However, these approaches apply simple shortcut distillation models ${ }^{7}$ to support the design task in an attempt to avoid the numerical problems encountered when optimising more rigorous simulation models. The use of these shortcut models can lead to large errors, as they often cannot accurately predict the behaviour of the complex crude oil distillation unit ${ }^{8}$. These shortcut models are also restricted to specific column configurations, which limits their applicability.

This work applies a simulation-optimization approach for the design of crude oil distillation units that integrates a rigorous tray-by-tray model of the distillation unit implemented in a commercial process simulator (Aspen HYSYS v8.6) with an optimization algorithm coded in Matlab R2015a. The optimization of process simulation models using external algorithms was addressed in other works ${ }^{10-12}$, but to the best of our knowledge none of them applied this approach to the design of complex crude-oil distillation units. In essence, these approaches decouple the simulation from the optimization in order to simplify the modelling and subsequent optimization of the process model. The process model is thus implemented in a simulation package that solves a system of nonlinear equations, while the optimization is carried out by an external algorithm that seeks the best values of the independent values by iteratively interrogating the process model.

As will be later discussed in the article, these approaches differ in the optimization algorithm employed, which can be a deterministic method (e.g. gradient based) or based on stochastic optimization algorithms (e.g. genetic algorithms, simulated annealing). Hence, when applied to the design of complex distillation units, the simulation-optimization approach takes advantage of the physical property and thermodynamic models, as well as the crude oil characterization and column hydraulic models available in the process simulator. These tailored models ultimately lead to more accurate results compared with the use of shortcut methods. In addition, the rigorous simulation environment is more versatile, allowing for a more flexible modelling of the column configuration. Furthermore, heat recovery opportunities for each proposed design were determined in this work using an open source algorithm implemented in Matlab ${ }^{13}$. Following this approach, pinch analysis was used 
iteratively to perform heat integration calculations for the designs proposed by an external optimizer.

The remainder of this article is organised as follows. Section 2 reviews existing methodologies for the design of crude oil distillation units. In Section 3, a superstructure representing the crude oil distillation unit is proposed and a detailed optimization formulation is presented together with a customized solution procedure. The solution procedure makes use of readily available commercial process simulator to simulate the crude oil distillation column, hence avoiding the need to formulate the complex column using explicit equations; moreover, the process simulator environment is versatile and user-friendly, thus making our approach easier to implement in practice and accessible to industrial practitioners. Section 4 introduces a case study that illustrates the capabilities of the proposed design methodology. The conclusions of the work are finally presented in Section 5.

\section{Previous research on crude oil distillation unit design}

In the past decades, various methods have been proposed and developed for the design of crude oil distillation units. Conventional methods apply heuristic rules, experience, empirical correlations and simple relationships. For instance, the number of trays in each section of the column and the stripping steam are often estimated based on empirical correlations obtained from previously established designs ${ }^{4}$. Similarly, in Watkins ${ }^{5}$ method, the number of trays in each section of a column is selected from a predetermined range, while the stripping steam flow is estimated based on product flow rates. The approaches of Nelson ${ }^{4}$ and Watkins ${ }^{5}$ formed the basis for many subsequent design methodologies for crude oil distillation units that involve iterations and trial and error procedures. Furthermore, the heat recovery network is omitted in these design approaches, which neglect the complex interactions between such a network and the distillation column.

Other research has focused on developing integrated design methods that address the design of the crude oil distillation unit and the associated heat recovery network simultaneously. Along these lines, Liebmann and co-workers ${ }^{1,14}$ combined rigorous column models and pinch analysis to design a crude oil distillation unit. Their approach takes design decisions in a sequential manner considering heat recovery at each step using pinch analysis. To avoid the

numerical difficulties associated with the rigorous simulation of the column, Sharma ${ }^{15}$ 
proposed to use the concept of a column grand composite curve ${ }^{16}$. This strategy identifies the maximum amount of energy that can be recovered without affecting the separation. A limitation of this approach is that the role of the stripping steam is neglected. Bagajewicz and $\mathrm{J}^{17}$ focused on overcoming the above limitation, incorporating the effect of the stripping steam on the maximum heat recovery of a crude oil distillation column and introducing the concept of a heat demand-supply diagram. This approach, however, does not account for the trade-off between capital and energy costs.

To design an integrated process system, it is necessary to design the complex column and the heat recovery network simultaneously. For example, Suphanit ${ }^{7}$ applied the column decomposition strategy of Liebmann and co-workers ${ }^{1,14}$ to develop a shortcut model for the crude oil distillation column. This model was then used within an optimization framework together with pinch analysis to simultaneously optimise distillation operating variables and the heat recovery network (utility demand and area) so as to minimize the total annualized cost. Rastogi ${ }^{8}$ extended the shortcut model of Suphanit ${ }^{7}$ to account for column pressure drop and pump-around location. A detailed model of both the heat exchanger network and the distillation column was incorporated into an optimization framework that optimized the column structure and operating conditions. $\mathrm{Chen}^{9}$ modified the shortcut models of Rastogi ${ }^{8}$ to allow for other pump-around locations and also modelled temperature-dependant properties of process streams undergoing phase change. In this work, the structure and operating conditions of the column together with the heat exchanger network were optimized using simulated annealing.

A comprehensive overview of optimization methods applied to process synthesis and design can be found in the excellent work of Grossmann et al. ${ }^{18}$ and Grossmann and GuillénGosálbez $^{19}$. The optimization methods have been applied to design several chemical processess (other than crude oil distillation units) ${ }^{20-24}$.

Several conclusions can be drawn from the literature review presented above. Traditional distillation design methods do not simultaneously consider heat recovery. Integrated design approaches do consider both, the column and the heat recovery network, but seldom analyse the trade-offs between capital and energy cost in a rigorous way. Optimization techniques have been used to design the column and heat recovery network ${ }^{7-9}$. However, to simplify the 
calculations, most of these approaches rely on shortcut distillation models ${ }^{7}$ that provide less accuracy and versatility. No approaches have been identified that directly use rigorous distillation models for optimization-based design of heat-integrated crude oil distillation systems.

This research introduces a systematic framework for the design of heat-integrated crude oil distillation units that overcomes the limitations of established methods. Our approach applies rigorous tray-by-tray distillation column models to simulate alternative designs. These models are combined with a genetic algorithm that optimizes the column design. The number of trays in each column section together with the operating conditions (including the feed inlet temperature, pump-around duties and temperature drops, stripping steam flow rates and reflux ratios) are selected to minimize the total annualized cost. This cost accounts for the annualized capital cost and annual operating costs related to fuel consumption in the furnace.

\section{Optimization-based design approach}

This section presents a simulation-optimization based approach for the design of crude oil distillation units. First, the rigorous tray-by-tray model used to simulate the crude oil distillation column is discussed. Then, the mathematical formulation of the optimization problem is presented. Next, an approach proposed to solve the optimization problem is described. We emphasize that we are dealing here with a very complex crude oil distillation system for which many decisions (including pump arounds, diameters and number of trays in different sections and operating conditions) must be optimized all together while considering the design of the HEN coupled with the unit. Developing a short-cut method for such a system is a very challenging task that would very likely result in larger approximation errors.

\subsection{Crude oil distillation unit simulation model}

In process design, it is crucial that models used to simulate design options are sufficiently realistic to deliver feasible solutions. Two main types of models are available for design of crude oil distillation units, namely, shortcut models ${ }^{7-9}$ and rigorous models ${ }^{14,17}$. The shortcut models adapt the Fenske-Underwood-Gilliland design equations for simple columns. These models predict the number of trays in each column section and operating conditions, such as 
reflux and reboil ratios. When applied to crude oil distillation, these models are restricted in terms of allowable configurations and accuracy of the predictions.

On the other hand, the so-called rigorous models apply material and energy balances as well as equilibrium relations in every stage of the column ${ }^{25}$. These models provide more accurate predictions. However, they are more difficult to handle due to the need to start the calculations from a very good initial guess in order to avoid convergence problems. Procedures for solving rigorous models are well established, and have been implemented in commercial process simulation software such as Aspen HYSYS, Aspen Plus, UNISIM, and PRO II. Such software allows designers to simulate complex distillation column flowsheets using iterative and sequential modular algorithms. Here, there is no need to define in an explicit form the model equations, as they are already implemented in the process simulator. Simulation packages like ASPEN, HYSYS or gPROMS already contain specific routines to solve distillation columns (and other unit operations) that are highly efficient. In this work, without loss of generality, the 'rigorous' distillation model available in Aspen HYSYS v.8.6 is used to simulate the crude oil distillation column. Section 3.3 presents a detailed description of how the rigorous column model is built.

\subsection{Heat recovery consideration}

In general, heat recovery is carried out using a heat exchanger network (HEN). After fixing the process configuration and operating conditions, information on process streams (i.e., inlet and outlet temperatures and duties of all streams requiring heating and cooling) becomes available. This information could be used to design the HEN, which determines the minimum utility requirements that will be used to evaluate the design options.

In an optimization-based design, many options need to be evaluated before selecting the best alternative. In this context, designing a full HEN for each potential design would require significant computational effort. This is because the HEN design can itself be posed as a nonconvex MINLP problem that is per se hard to solve, mainly due to the presence of bilinear terms in the constraints as well as concave ones in the objective function ${ }^{26}$. While there have been some recent attempts to solve the HEN design problem more efficiently ${ }^{21}$, the methods proposed still scale poorly with the number of hot and cold streams. To overcome this limitation, pinch analysis is applied here. Hence, targets for minimum utility requirement are determined to screen the design options and propose improvements for 
existing designs ${ }^{17}$. In this work, the grand composite curve is coded in Matlab R2015a ${ }^{10}$ and incorporated into the optimization procedure to calculate minimum utility requirements for the crude oil distillation unit. Detailed HEN design is not addressed. Nevertheless, pinch analysis is expected to minimize the dominant cost, i.e. fired heating, and it is well known that utility costs dominate distillation process economics. It is anticipated that the annualized HEN capital costs will be relatively similar for different column designs. Future work intends to account for HEN details.

\subsection{Crude oil distillation column modelling - superstructure formulation}

In this section, the column superstructure used to design the crude oil distillation column is developed. A process superstructure considers (ideally) all possible design alternatives simultaneously. The superstructure of the complex heat-integrated crude oil distillation column is built treating Murphree tray efficiencies ${ }^{27}$ as binary variables that can activate or deactivate trays (following the approach developed by Yeomans and Grossmann ${ }^{28}$ and Caballero et. al. $\left.{ }^{10}\right)$. In this approach, a column section containing equilibrium stages includes a set of 'temporary' trays (also known as inactive trays) and 'permanent' trays (also known as active trays). On a permanent tray, mass transfer takes place between the vapour and liquid phases; it is assumed that phase equilibrium is achieved. On a temporary tray, no mass transfer takes place; the temporary tray is modelled as a by-pass with inputs equal to the outputs in each phase. In a commercial process simulator, trays can be modelled by setting appropriately their Murphree tray efficiency ${ }^{27}$ : zero (when the tray is inactive) or one (when it is active). On both types of trays, the material and energy balances and equilibrium relations are solved. However, on a temporary tray, no separation takes place. Figure 2 illustrates the superstructure for modelling the crude oil distillation column. 


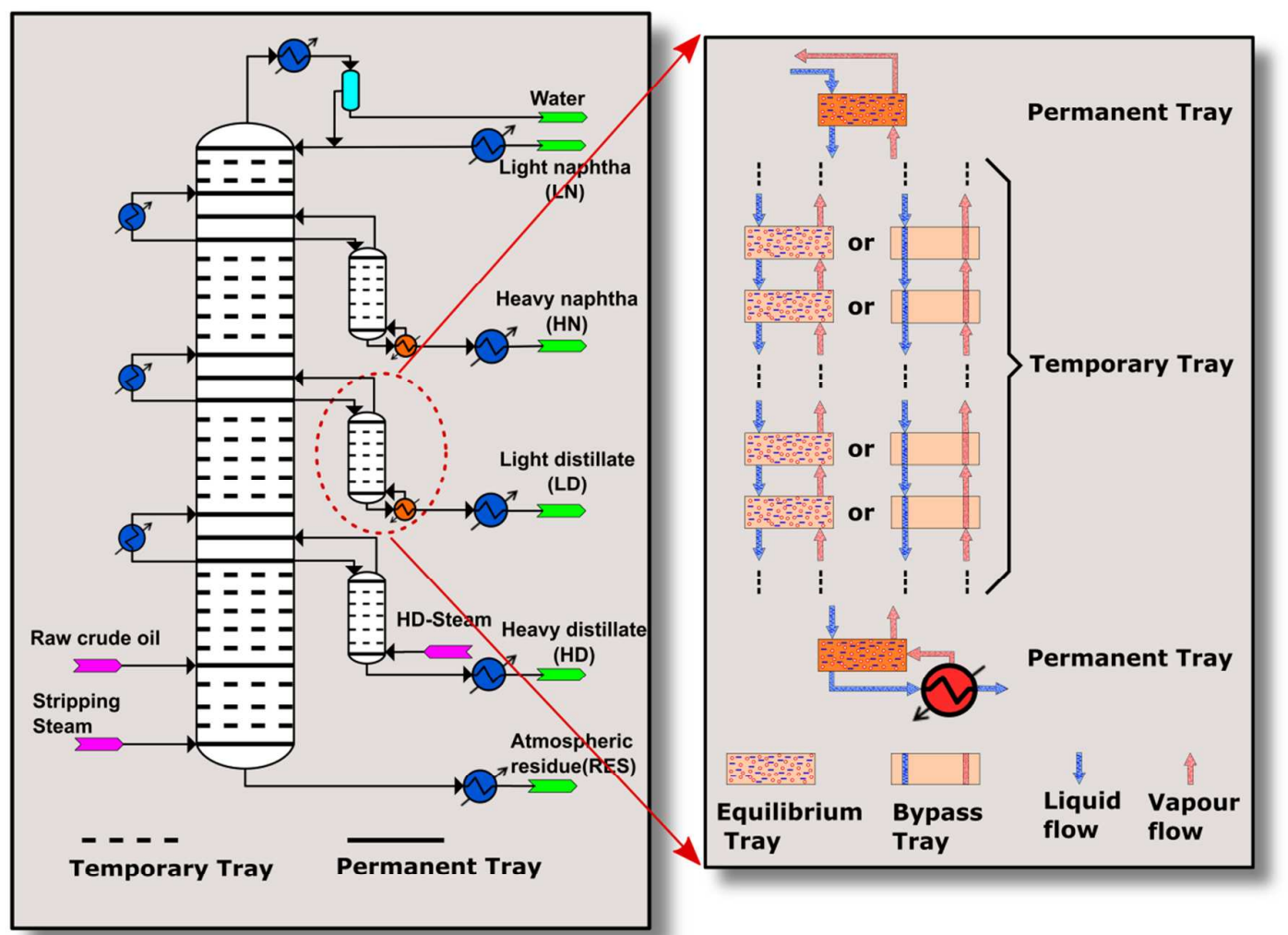

Figure 2 Superstructure representation of crude oil distillation column

As shown in Figure 2, the column superstructure consists of eight sections: five sections in the main column and three side strippers. The initial number of trays in each column section can be selected using traditional methods ${ }^{4,5}$ or shortcut models ${ }^{7-9}$. In the superstructure, each section is set up to ensure that more trays are available than will be needed. During optimization, the optimal number of trays in each section will be determined. The minimum possible number of permanent (active) trays in the superstructure is $18 ; 12$ in the main column and 2 in each side stripper. These trays are located at points where a stream enters or leaves the column.

\subsection{Mathematical formulation}

The crude oil distillation column design problem can be formulated as an MINLP model (M1) based on the superstructure proposed in Figure 2:

(M1) $\quad \min _{x_{S}, x_{O}} \quad \psi\left(x_{D}, x_{S}, x_{O}\right)$ 


$$
\begin{array}{ll}
\text { s.t. } & h_{I}\left(x_{D}, x_{S}, x_{O}\right)=0 \\
& h_{E}\left(x_{D}, x_{S}, x_{O}\right)=0 \\
& g_{E}\left(x_{D}, x_{S}, x_{O}\right) \leq 0
\end{array}
$$

$$
x_{D} \in X_{D}, x_{S} \in X_{S}, x_{O} \in X_{O}
$$

where $\psi$ is the objective function; $h_{I}$ denotes the set of implicit equality constraints representing material, energy and thermodynamic equations embedded in the process simulator; $h_{E}$ is the set of explicit equality constraints while $g_{E}$ is the set of inequality constraints. $X_{D}, X_{S}$ and $X_{O}$ are the feasible sets for the decision variables, namely $x_{D}, x_{S}$ and $x_{O}$, which represent dependent, structural and operational variables, respectively. The dependent variables are calculated by the simulator for fixed values of $X_{S}$ and $X_{O}$.

For the crude oil column design problem, the inequality constraints can be more specifically formulated as in Model M2:

$$
\begin{array}{ll}
\min _{x_{S}, x_{O}} & \psi\left(x_{D}, x_{S}, x_{O}\right) \\
& \\
\text { s.t. } & h_{I}\left(x_{D}, x_{S}, x_{O}\right)=0 \\
& h_{E}\left(x_{D}, x_{S}, x_{O}\right)=0 \\
& g_{1}: l b_{i} \leq N_{i} \leq u b_{i} \quad i=1,2,3, \ldots, N_{\text {section }} \\
& g_{2}: l b_{j} \leq Q_{P A, j} \leq u b_{j} \quad j=1,2,3 \\
& g_{3}: l b_{j} \leq \Delta T_{P A, j} \leq u b_{j} \quad j=1,2,3 \\
& g_{4}: l b_{k} \leq F_{S, k} \leq u b_{k} \\
& g_{5}: l b \leq R \leq u b \\
& g_{6}: l b \leq T_{F} \leq u b \\
& g_{7}: l b_{l} \leq T 5_{l} \leq u b_{l} \quad l=1,2 \\
& g_{8}: l b_{l} \leq T 95_{l} \leq u b_{l} \quad l=1,2, \ldots, N_{\text {product }}
\end{array}
$$

where $N_{\mathrm{i}}$ is the number of active trays in column section i; $Q_{\mathrm{PA}, \mathrm{j}}$ and $\Delta T_{\mathrm{PA}, \mathrm{j}}$ are the duty and temperature drop of pump-around $\mathrm{j} ; F_{\mathrm{S}, \mathrm{k}}$ is the steam flow rate of stream $\mathrm{k} ; R$ is the overhead 
reflux ratio; $T_{\mathrm{F}}$ is the feed inlet temperature; and $T 5_{l}$ and $T 95_{l}$ are the boiling temperatures of product $l$ at $5 \%$ and $95 \%$ vaporization (according to ASTM standards; note that other specifications could be defined in a similar way).

In Model M2, $g_{1}$ to $g_{6}$ are bounds on structural and operational variables, while $g_{7}$ and $g_{8}$ represent constraints on product quality in terms of ASTM D86 boiling temperature: T5 and T95. To enhance the numerical robustness of the model, it is advantageous to include the latter constraints (product quality) in the objective function via penalty terms ${ }^{21}$. The resulting formulation, M3, is:

$$
\begin{array}{ll}
\text { (M3) } \min _{x_{S}, x_{O}} \Psi\left(x_{D}, x_{S}, x_{O}\right)+\left[\Pi \sum_{i=1}^{n}\left[\max \left(0,\left(g_{i}\right)\right)\right]^{2}\right] \\
\text { s.t. } & h_{I}\left(x_{D}, x_{S}, x_{O}\right)=0 \\
& h_{E}\left(x_{D}, x_{S}, x_{O}\right)=0 \\
& g_{1}, g_{2}, g_{3}, g_{4}, g_{5}, g_{6}
\end{array}
$$

where $g_{i}$ denotes the inequality constraints $g_{7}$ and $g_{8}$; $\Pi$ is a scalar parameter that scales the magnitude of the violation of constraints, and hence ensures that the product quality specifications are maintained during the optimization. Note that this penalty term can be easily formulated using slack variables.

\subsubsection{Objective function}

The aim of the optimization-based design task is to search for those process structure and operating variables that best achieve a desired objective. Different types of objective functions are relevant, for example, net profit, energy cost, net present value and total annualized cost. The most appropriate objective function to be used depends on the aims of the design. For grassroots design, a suitable objective is to minimize the total annualized cost (TAC), as it accounts for the trade-off between capital investment and operating expenses. The total annualized cost is the sum of the total operating cost (OC) and annualized capital cost (ACC):

$$
T A C=O C+A C C
$$


For the particular case of crude oil distillation unit, the most significant operating costs are the cost of stripping steam and of hot and cold utilities, usually fuel for fired heating and cooling water. Pinch analysis allows minimum utility requirements to be calculated ${ }^{29}$ for a given set of heating and cooling duties. In this way, opportunities for heat recovery are accounted for during the design optimization.

$$
O C=\sum_{i=1}^{n} S T_{i} \cdot C_{S T, i}+H U . C_{H U}+C U . C_{C U} \quad n=2
$$

In Eq. (5), $C_{S T}, C_{H U}$ and $C_{C U}$ are the unit costs of stripping steam, hot and cold utilities, respectively; $H U$ and $C U$ are minimum hot and cold utilities, respectively, while $n$ represents the number of stripping steam streams associated with the column.

The annualized capital cost is the installed cost of the column shells $\left(S_{c}\right)$ and the installed cost of trays within the column, $\left(T_{C}\right)$, multiplied by an annualization factor $\left(A_{f}\right)^{29}$.

$$
\begin{aligned}
& A C C=\left(S_{c}+T_{C}\right) * A_{f} \\
& A_{f}=\frac{i(1+i)^{t}}{(1+i)^{t}-1}
\end{aligned}
$$

where $i$ is the interest rate and $t$ is the plant life.

\subsubsection{Cost models}

The column shell and tray costs are estimated using the correlations proposed by Guthrie ${ }^{30}$.

$$
S_{C}=\left(\frac{M \& S \text { Index }}{2011}\right) 101.9(D)^{1.066}(H)^{0.802}\left(2.18+F_{c 1}\right)
$$

where M\&S Index 2011 is the Marshall and Swift chemical equipment cost index for year 2011 $\left(4^{\text {th }}\right.$ quarter) ${ }^{31}$, allowing costs to be updated from 1969 (when the M\&S Index was 280); the cost is updated to current equipment cost using Eq. (10); $D$ is the sectional diameter of the 
column, $H$ is the sectional height, which depends on tray spacing and $F_{c 1}$ is the column cost factor, which depends on the column material of construction and column operating pressure.

$$
T_{C}=\left(\frac{M \& S \text { Index } 2011}{280}\right) 4.7(D)^{1.55} H F_{c 2}
$$

The tray cost factor $F_{c 2}$ depends on the type of tray, tray spacing and material of construction.

$$
\left(\frac{C E P C I_{2014}}{C E P C I_{2011}}\right) \times \operatorname{Cost}_{2011}
$$

where $\mathrm{CEPCI}_{2011}$ and $\mathrm{CEPCI}_{2014}$ are the chemical engineering plant cost index for year 2011 $\left(4^{\text {th }} \text { quarter }\right)^{31}$ and 2014 ( $4^{\text {th }}$ quarter $)^{32}$ respectively; Cost $_{2011}$ is the equipment cost for year 2011, calculated using Eq. (8) and Eq. (9). The M\&S Index $2011, \mathrm{CEPCI}_{2011}$ and $\mathrm{CEPCI}_{2014}$ are $1536.5,590.1$ and 575.7 respectively.

The column diameter and height for a specific type of internal are determined using hydraulic models, as discussed in the Section 3.4.3.

\subsubsection{Hydraulic models}

In crude oil distillation column design, hydraulic analysis is required to identify an appropriate tray selection and to avoid entrainment (or jet flooding), weeping, coning and downcomer flooding ${ }^{25}$. Different design and types of trays and packings (e.g. sieve tray, valve tray, high capacity tray) have a specific range of satisfactory vapour and liquid flow rates, defined by upper and lower bounds ${ }^{25,33,34}$. Therefore, the column diameter has to be sized appropriately to accommodate the flows of vapour and liquid in the column, and also provide enough active area for mass transfer ${ }^{25}$, without incurring an excessively high pressure drop. The tray spacing needs to be chosen in order to avoid entrained liquid jetting onto the tray above ${ }^{25}$. Furthermore, the downcomers should have sufficient area to allow liquid flow ${ }^{25}$. Established methods are available for column sizing and selection of internals ${ }^{25,34,35}$, many of which have been implemented in commercial process simulators. In this work, the column sizing capabilities implemented in the tray sizing utility of Aspen HYSYS v8.6 are employed to carry out the hydraulic calculations. The column diameter obtained from this calculation, 
together with the column height (determined based on permanent trays), are used to determine the purchase cost of the column.

\subsection{Solution procedure}

The optimization of the column naturally leads to an MINLP problem containing nonlinear equations and binary as well as continuous variables. Various approaches have been developed and proposed to solve this type of problem. These approaches can be broadly classified as deterministic (gradient-based) methods ${ }^{36-39}$ and stochastic (derivative-free) methods ${ }^{36,40}$. A detailed discussion of MINLP algorithms can be found elsewhere ${ }^{36-41}$. Note that our MINLP is not defined in a fully explicit manner, but rather via both explicit and implicit equations implemented in the simulator and in an external modelling system (i.e., Matlab). MINLP problems encountered in the simulation-optimisation of chemical processes can be solved by several methods. Caballero et al. ${ }^{10}$ applied gradient-based methods to solve one such MINLP, which was decomposed into two levels following an outer-approximation scheme. In this work, at the lower level continuous variables are optimized for a fixed design by solving an NLP problem in which a gradient-based NLP solver iterates with the simulation model. At the upper level, new designs encoded in the values of the binary variables are generated by solving an MILP. This MILP is constructed by linearizing the nonlinear equations at the optimal solution of the NLP. These two levels are solved iteratively until they converge towards a final solution considering a given stopping criterion. Stochastic approaches, on the other hand, attempt to solve the MINLP in a simultaneous way by optimising the decisions variables all together and without relying on gradient-based methods. The standard approach here is to combine metaheuristics (e.g. simulated annealing, genetic algorithms, etc.) with the simulation model and let them iterate for a given time.

Since Model M3 is nonlinear and non-convex, standard deterministic methods can only guarantee convergence to a local optimum. Furthermore, obtaining the derivatives of the NLP might be difficult, which may lead to convergence problems when applying gradient-based NLP algorithms. To overcome these limitations, this work applies a stochastic global search method to solve M3 based on genetic algorithms (GA). We note that, despite the various strategies implemented in the GA, this approach is unable to guarantee convergence to the global optimum. Global optimality can only be ensured using deterministic methods, but 
these require the explicit form of the equations. In our case, these equations are implemented by the simulator, which does not provide direct access to the equations.

The strategy proposed to optimize Model M3 is presented in Figure 3. The proposed approach combines a rigorous tray-by-tray crude oil distillation column model with cost models, a heat recovery model and a hydraulic model within a unified framework. This strategy searches for the best configuration and operating conditions that result in minimum total annualized cost. The crude oil distillation unit is simulated using a rigorous column model implemented in Aspen HYSYS v8.6, while the optimization algorithm is coded in Matlab R2015a. The exchange of information between Matlab R2015a and Aspen HYSYS v8.6 is established using the automation client-server application provided by Matlab R2015a.

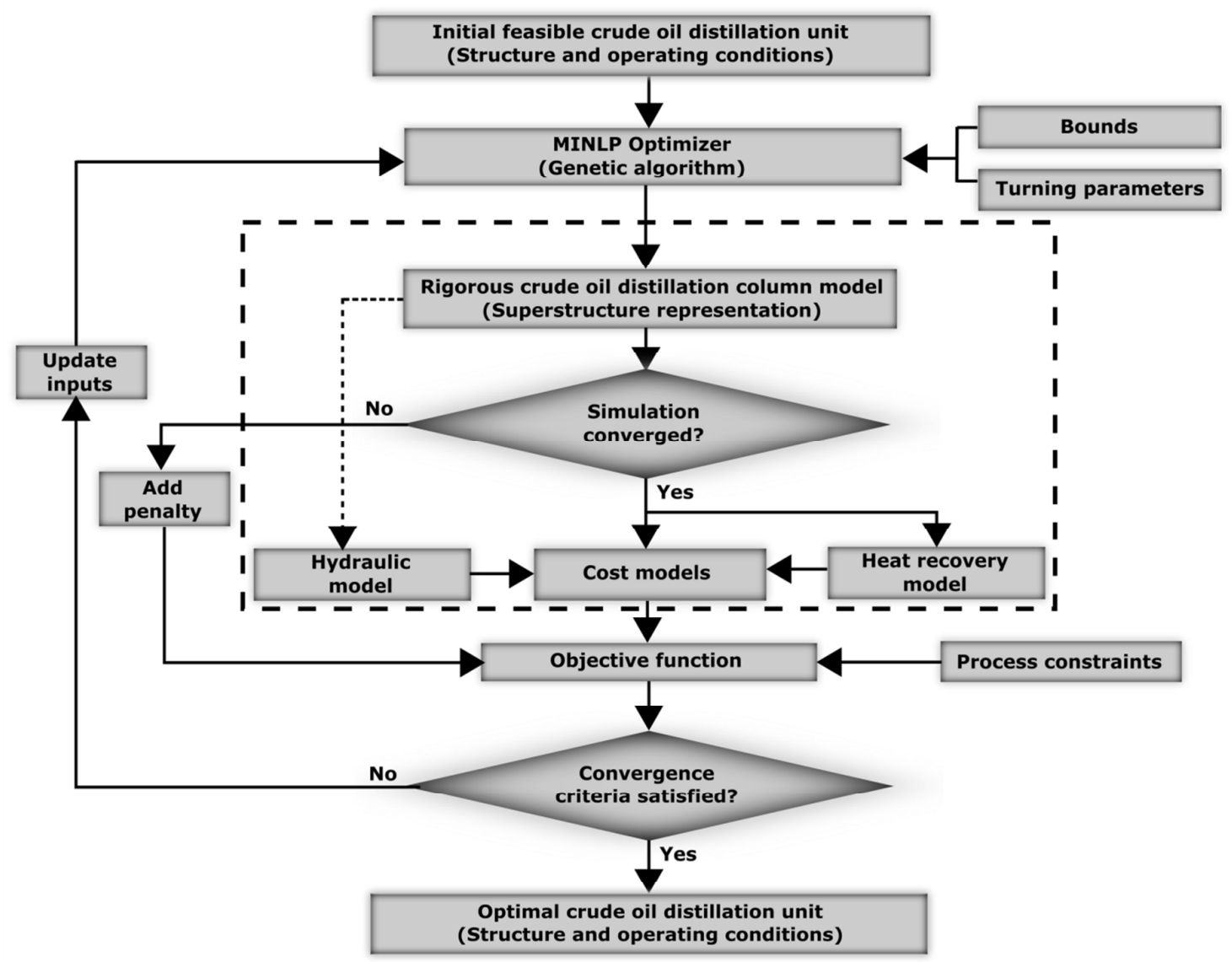

Figure 3 Framework for the optimization-based design of crude oil distillation unit 
The implementation of the proposed framework is carried out in two steps. The distillation column superstructure is first defined in the Aspen HYSYS environment. This superstructure contains dependent, structural and operational variables that will be optimized by the GA. The mixed integer non-linear programing model (M3) is solved by a GA implemented in Matlab. The overall MINLP model includes equality constraints (explicit and implicit), inequality constraints, bounds on optimization variables and the objective function. The interface established between Matlab and Aspen HYSYS facilitates the transfer of the data required to calculate the objective function value and to assess whether the constraints are met. Once the model is defined, and the link between Matlab and Aspen HYSYS has been established, an optimization algorithm (e.g. genetic algorithm) is employed to search for the optimal column design.

Hence, in each iteration, the genetic algorithm proposes the column structure and operating conditions to be simulated in the rigorous column model. Process stream information from the converged column flowsheet is used by the heat recovery model to calculate the minimum hot and cold utility demand. For each permanent (active) tray inside the column, the vapour and liquid flow rates and fluid properties are calculated and used in the hydraulic model to determine the column diameter (using the tray sizing utility within the Aspen HYSYS v8.6 simulation environment). The column diameter and height, utility targets and steam flow rates are used to calculate the objective function. This objective value is used to guide the search for an optimal set of structural and operational variables that minimize the column total annualized cost. Certain combinations of inputs proposed by the optimization algorithm may lead to an infeasible simulation of the rigorous column, which may consequently halt the algorithm. This issue is overcome by adding a large penalty to the objective function whenever the column simulation fails. As discussed later in detail, numerical results show that this strategy leads to feasible designs that do not violate any inequality. The section that follows provides more detail about the genetic algorithm.

\subsubsection{Optimization algorithm}

The genetic algorithm falls into the class of stochastic optimization methods known as evolutionary programming. Genetic algorithms have been successfully applied to many complex chemical engineering problems ${ }^{42-45}$. The algorithm handles both integer decisions 
and continuous variables and does not require derivative information. Therefore, discontinuous functions can be handled with ease.

The implementation of the genetic algorithm involves four fundamental steps, namely, generation of a random population of individuals, evaluation of fitness of individuals, and selection of the best individuals and reproduction using genetic operators (cross-over and mutation) in order to create the population for the next generation ${ }^{46}$. Figure 4 provides an overview of how these steps evolve to an optimal solution. A detailed description of each step follows.

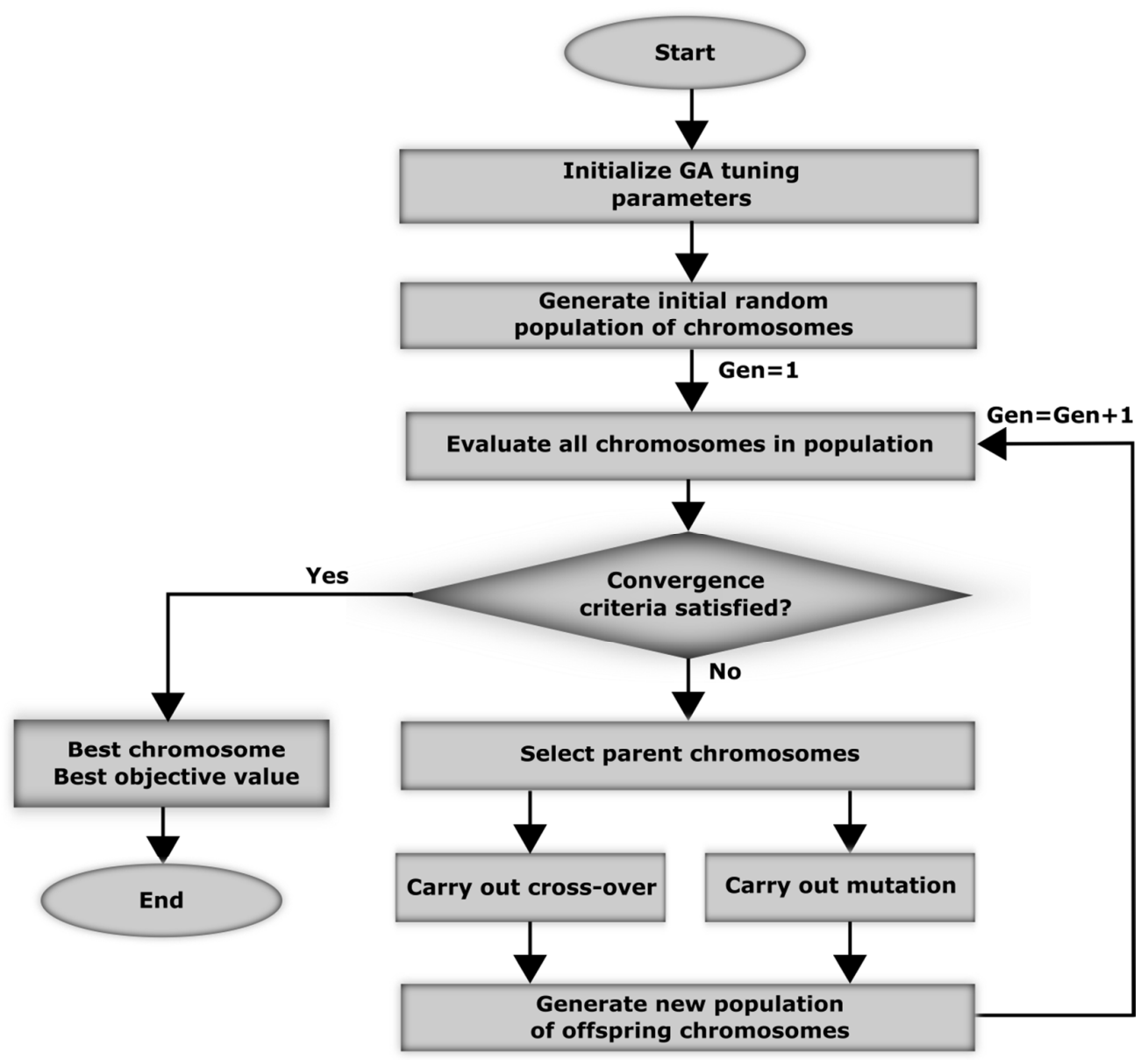

Figure 4 Solution strategy based on genetic algorithm (adapted from Odjo et al. ${ }^{42}$ )

\section{Step 1: Generation of random population of chromosomes}

The first step in the implementation of the genetic algorithm involves the generation of a random population of chromosomes (or individuals), which represents alternative structure 
and operating conditions of the crude oil distillation unit within the search space. The search space is defined by lower and upper bounds on the optimization variables and by a set of equality constraints that are defined implicitly in the simulation that enable the assessment of the units' performance. Each chromosome contains 18 genes: 8 integer variables representing the number of trays in each column section and 10 continuous variables representing feed inlet temperature, pump-around duties and temperature drops, stripping steam flow rates and reflux ratio. This number of genes comes from an analysis of degrees of freedom in our systems. Note that other combinations of variables could be defined. However, numerical examples show that this particular choice leads to a system that is numerically more robust than others, meaning that there are fewer solutions proposed by the genetic algorithm that do not convergence in the simulator. The total number of chromosomes in a generation, the population size, is usually pre-specified by the designer.

\section{Step 2: Evaluation of individual fitness}

In this step, all the chromosomes generated in Step 1 representing alternative designs are simulated on the rigorous distillation column model in HYSYS in order to determine their relative fitness. The fitness function is usually the objective function of the optimization problem, which in this case corresponds to the total annualized cost. The specifications in the simulation are as follows: product quality, boil-up ratio(s), reflux ratio(s), pump-around duties and temperature drops. Chromosomes leading to simulations that do not convergence are penalised to prevent the genetic algorithm from proposing similar solutions again. Similarly, solutions that do converge but violate at least one constraint are also penalised.

\section{Step 3: Selection of best individuals}

All the members of the population are evaluated in terms of their fitness. High scores are assigned to members with high fitness and low scores to those with low fitness. High performing chromosomes (also called parents), i.e. alternative designs with minimum total annualized cost are later chosen for reproduction (cross-over or mutation). Some of these high performing chromosomes (elites count) are retained and passed forward to the subsequent generation without changing their form ${ }^{47}$.

\section{Step 4: Reproduction}


Reproduction consists of two operations, namely, cross-over and mutation. For the cross over operation, two parents are selected at random, and then some part of the genetic information (i.e. number of trays in column sections, feed inlet temperature, pump-around duties and temperature drops, stripping steam flow rates and reflux ratio) of one parent is swapped with the other to create two new chromosomes ${ }^{47}$. Mutation involves random alteration of the genetic information (either number of trays in column section or operating conditions) of one

parent to produce a new chromosome ${ }^{47}$. This operation helps to ensure diversity of the population and to prevent the algorithm from been trapped in a locally optimal solution ${ }^{47}$.

The steps listed above are repeated several times until one of the convergence criteria is satisfied. In this work, as convergence criteria we use the maximum number of generations and population convergence. The former establishes a maximum number of iterations after which the algorithm terminates while the latter stops when the difference in performance between two consecutive populations is less than a given tolerance. On termination, the bestperforming solution in the latest population and the corresponding objective function value are reported as the optimal solution to the design problem (provided all the constraints are met, otherwise the calculations are repeated using larger penalties). Implementation of the methodology is illustrated in a case study in the next section.

\section{Case study}

This section demonstrates the capabilities of the novel design approach.

\subsection{Problem description}

The case study is based on that presented by $\mathrm{Chen}^{9}$ and concerns the design of a crude oil distillation unit that separates $100,000 \mathrm{bbl} /$ day $\left(662.4 \mathrm{~m}^{3} \mathrm{~h}^{-1}\right)$ of Venezuelan Tia Juana light crude oil ${ }^{5}$ into five products, namely, light naphtha (LN), heavy naphtha (HN), light distillate (LD), heavy distillate (HD) and residue (RES). The details of the crude oil assay are presented in Tables S1 and S2 in the supporting information.

The initial column design consists of a main column with three pump-arounds and three sidestrippers, as shown in Figure 5. The main column has five sections (S-1 to S-5) with 5, 9, 10, 8 and 9 trays, respectively. The HD, LD and HN side-strippers have 5, 7 and 6 trays, respectively. The operating conditions, product quality (in terms of ASTM 5\% and 95\% 
boiling temperature) and flow rates are presented in Tables S3 and S4 in the supporting information. The column operates at a uniform pressure of 2.5 bar.

Sieve trays are assumed in the column hydraulic calculations. In all sections of the main column, four passes per tray are used, while two pass trays are used in the side-strippers. The main column and all side-strippers are sized based on an $85 \%$ approach to jet flooding, $50 \%$ approach to downcomer and a tray spacing of 0.609 meters.

The economic evaluation assumes an interest rate of 5\%, a plant life of 20 years and 8,700 operating hours per year. The initial column cost and costs of utilities are presented in Tables S5 and S6 in the supporting information. A minimum approach temperature of $30{ }^{\circ} \mathrm{C}$ is used to calculate minimum utility requirements.

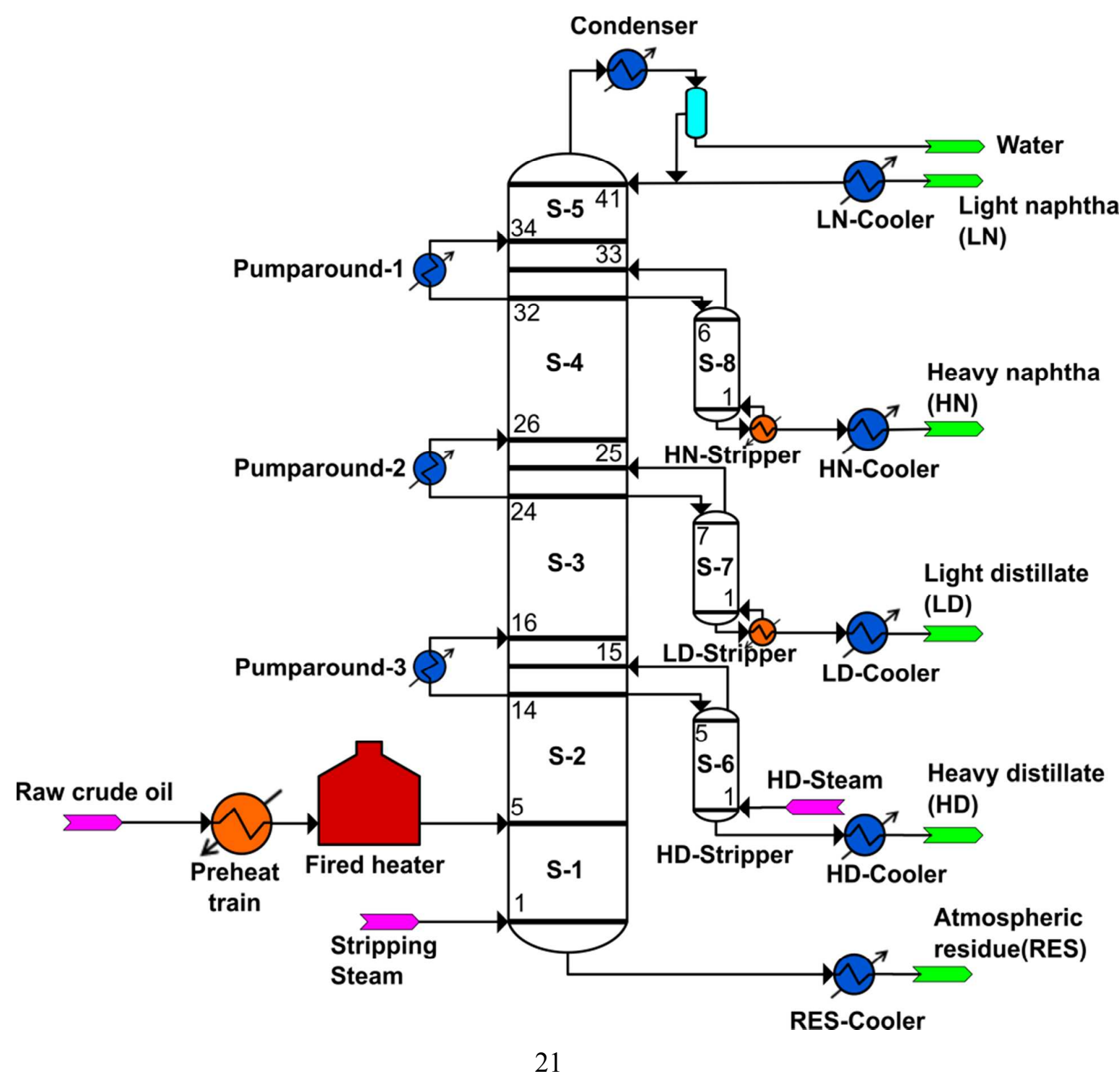


Figure 5 Case study: crude oil distillation unit design.

\subsection{Initialization of the column optimization}

The pre-optimization step starts by building the column superstructure that embeds all design alternatives using the approach presented in Section 3.3. The proposed superstructure for this case contains of $6,10,11,9$ and 10 trays in Sections S- 1 to S-5 of the main column, and 6, 8 and 7 in the HD, LD and HN side-strippers respectively. Table 1a shows the lower and upper bounds on the number of trays in each column section.

Table 1a Bounds on numbers of trays per column section

\begin{tabular}{cccc}
\hline Section & Lower bound & Upper bound & Initial value \\
\hline 1 & 3 & 6 & 5 \\
2 & 7 & 10 & 9 \\
3 & 8 & 11 & 10 \\
4 & 6 & 9 & 8 \\
5 & 7 & 10 & 9 \\
6 & 3 & 6 & 5 \\
7 & 5 & 8 & 7 \\
8 & 4 & 7 & 6 \\
\hline
\end{tabular}

The lower bounds indicate the minimum number of active trays in each column section, and the difference between the upper and lower bound indicates the maximum number of temporary (inactive) trays, the existence of which is determined by the optimization algorithm. To complete the definition of the search space, bounds are defined for the operating conditions in Table $1 \mathrm{~b}$. 
Table 1b Bounds on operating conditions

\begin{tabular}{lccc}
\hline Operating condition & Lower bound & Upper bound & Initial value \\
\hline PA 1 duty $(\mathrm{MW})$ & 8.40 & 14.00 & 11.2 \\
PA 2 duty $(\mathrm{MW})$ & 13.42 & 22.36 & 17.89 \\
PA 3 duty $(\mathrm{MW})$ & 9.63 & 16.05 & 12.84 \\
PA 1 DT $\left({ }^{\circ} \mathrm{C}\right)$ & 10 & 30 & 20 \\
PA 2 DT $\left({ }^{\circ} \mathrm{C}\right)$ & 40 & 60 & 50 \\
PA 3 DT $\left({ }^{\circ} \mathrm{C}\right)$ & 20 & 40 & 30 \\
Main stripping steam $\left(\mathrm{kmol} \mathrm{h}^{-1}\right)$ & 900 & 1500 & 1200 \\
HD stripping steam $\left(\mathrm{kmol} \mathrm{h}{ }^{-1}\right)$ & 188 & 313 & 250 \\
Feed temperature $\left({ }^{\circ} \mathrm{C}\right)$ & 340 & 375 & 365 \\
Reflux ratio & 3.17 & 6.17 & 4.17 \\
\hline
\end{tabular}

The product quality specifications that must be satisfied are shown in Table S4 in the supporting information. An allowable range of $10^{\circ} \mathrm{C}$ is set for each product specification. Note that the initial design must be 'feasible'. This implies two things: the solution must meet the product specifications and the associated simulation must in turn converge in Aspen HYSYS v8.6.

\subsection{Optimization parameters}

The optimization aims to identify a column with the best structure and operating conditions, corresponding to the minimum total annualized cost. Due to the stochastic nature of the genetic algorithm, each optimization run is likely to reach a different solution. In order to search for the best solution obtainable, the genetic algorithm is run ten times consecutively.

The MINLP problem formulated in Section 3.4 is coded and solved in Matlab R2015a using the genetic algorithm implemented in the Global Optimization Toolboox, on a HP desktop PC with Intel(R) Core i5 processor running at $3.2 \mathrm{GHz}$, and $8 \mathrm{~GB}$ of RAM. The initial population contains 100 chromosomes and the maximum number of generations is set to 200 . These parameter values were determined by running the genetic algorithm multiple times to finally select those parameter values that represent a good compromise between computational effort and quality of the final solution. Details of the computational results for 
the multiple runs of the genetic algorithm are summarized in Tables S7 and S8 of the supporting information.

\subsection{Optimization results}

\subsubsection{Case 1: CDU design without constraint on product flow rate}

The best results found for the crude oil distillation unit are summarized in Figure 6 and Tables $2 \mathrm{a}$ to $2 \mathrm{c}$.

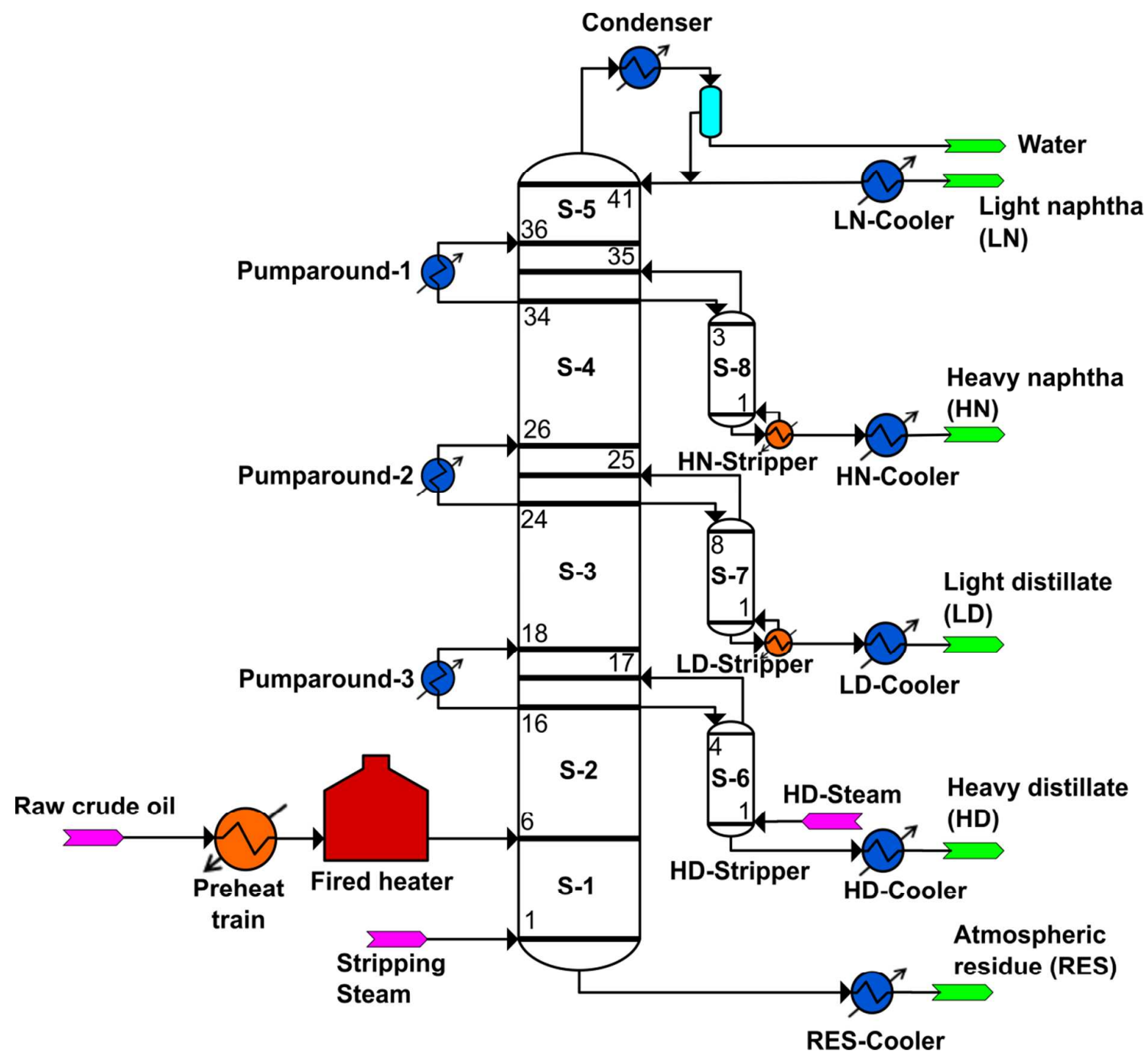

Figure 6 Optimal configuration of crude oil distillation unit (Case 1)

The column contains $6,10,8$, customized 10 and 7 trays in the five sections of the main column, and 4, 8 and 3 trays in HD, LD and HN side-strippers respectively. The minimum 
utility targets for the optimal column, as calculated by the grand composite curve, are 40.35 MW of hot utility and 41.71 of cooling utility (respectively). This corresponds to a total utility cost of $\$ 6.3$ million per annum $\left(\$ M M y^{-1}\right)$. It should be noted that the utility targets reflect the minimum amount of utility required by the column from a thermodynamic viewpoint, without taking into account heat exchanger network details. For a more detailed analysis, a heat exchanger network model will be required to replace the grand compose curve in the optimization framework. Nevertheless, the stream data for the optimal column presented in Table S9 of the supporting information can be used to design the heat exchanger network for the column. The column structure together with the steam and utility requirement lead to a total annualised cost of $7.84 \$ \mathrm{MM} \mathrm{y}^{-1}$.

Table 2a CDU operating conditions (Case 1)

\begin{tabular}{lcc}
\hline Variable & Initial value & Case 1 \\
\hline PA 1 duty $(\mathrm{MW})$ & 11.2 & 8.41 \\
PA 2 duty $(\mathrm{MW})$ & 17.89 & 13.44 \\
PA 3 duty $(\mathrm{MW})$ & 12.84 & 10.25 \\
PA 1 DT $\left({ }^{\circ} \mathrm{C}\right)$ & 20 & 29 \\
PA 2 DT $\left({ }^{\circ} \mathrm{C}\right)$ & 50 & 55 \\
PA 3 DT $\left({ }^{\circ} \mathrm{C}\right)$ & 30 & 34 \\
Main steam $\left(\mathrm{kmol} \mathrm{h}{ }^{-1}\right)$ & 1200 & 900 \\
HD steam $\left(\mathrm{kmol} \mathrm{h}{ }^{-1}\right)$ & 250 & 188 \\
Feed temperature $\left({ }^{\circ} \mathrm{C}\right)$ & 365 & 340 \\
Reflux ratio & 4.17 & 3.17 \\
\hline
\end{tabular}

Table 2b Product quality and flow rate (Case 1)

\begin{tabular}{c|cc|cc|cc}
\hline Products & \multicolumn{2}{|c|}{ T5\% $\left({ }^{\circ} \mathrm{C}\right.$, ASTM D86) } & \multicolumn{2}{|c|}{ T95\% $\left({ }^{\circ} \mathrm{C}\right.$, ASTM D86) } & \multicolumn{2}{c}{ Flow rates $\left(\mathrm{m}^{3} \mathrm{~h}^{-1}\right)$} \\
\hline & Initial value & Case 1 & Initial value & Case 1 & Initial value & Case 1 \\
\hline LN & 26 & 24 & 111 & 111 & 103.5 & 98.8 \\
HN & 139 & 129 & 187 & 187 & 78.2 & 86.6 \\
LD & 216 & 217 & 301 & 301 & 140.3 & 130.5 \\
HD & 311 & 304 & 354 & 354 & 48.1 & 45.3 \\
RES & 361 & 352 & 754 & 752 & 292.5 & 301.4 \\
\hline
\end{tabular}


Table 2c Utility demand and column cost (Case 1)

\begin{tabular}{lccc}
\hline Variable & Initial value & Case 1 & Units* $^{*}$ \\
\hline Utility requirements & & & \\
Hot utility & 54.61 & 40.35 & $\mathrm{MW}$ \\
Cold utility & 61.18 & 41.71 & $\mathrm{MW}$ \\
Cost & & & \\
Utility cost & 8.51 & 6.27 & $\$ \mathrm{MM} \mathrm{y}^{-1}$ \\
Steam cost & 1.77 & 1.33 & $\$ \mathrm{MM} \mathrm{y}^{-1}$ \\
& & & \\
Total operating cost & 10.28 & 7.60 & $\$ \mathrm{MM} \mathrm{y}^{-1}$ \\
Annualised capital cost & 0.33 & 0.25 & $\$ \mathrm{MM} \mathrm{y}^{-1}$ \\
Total annualised cost & $\mathbf{1 0 . 6 1}$ & $\mathbf{7 . 8 4}$ & $\$ \mathbf{M M ~ y}$ \\
\hline
\end{tabular}

As shown in Table 2b, all the 5\% and 95\% ASTM boiling temperatures are within $10{ }^{\circ} \mathrm{C}$ of the specified values; that is, no constraints on product quality are violated. On the other hand, the flow rates of the five products have varied compared to the initial values. The most significant change is the increase of the atmospheric residue (RES) flow rate, representing a loss of valuable products from the atmospheric crude oil distillation unit. Such a large change could be avoided by adding constraints on the product flowrates and/or including the value of products in the objective function (i.e., maximizing profit instead of minimizing cost). Section 4.4.2 explores the use of constraints to restrict the flow rate of the atmospheric residue to within realistic limits.

\subsubsection{Case 2: CDU design with constraint on product flow rate}

Figure 7 and Tables $3 \mathrm{a}$ to $3 \mathrm{c}$ present the best results for the crude oil distillation unit design including constraint on product flow rates. A summary of the computational results (multiple runs) for this case is presented in Table S8 of the supporting information. 
The total number of trays in the crude oil distillation unit is 48: 39 in the main column and 3 in each side-stripper. The stripping steam requirements for Case 2 are the same as in Case 1 . However, the hot and cold utility requirements have increased by $8.9 \%$ and $9.1 \%$ respectively. This results from the fact that in Case 2, the crude oil feed needs heating at higher temperature $\left(361^{\circ} \mathrm{C}\right)$ compare with Case $1\left(340^{\circ} \mathrm{C}\right)$. The heating is required to vaporize more valuable products from the crude oil feed, which are recovered in the distillation unit. The additional heating is performed at the expense of increasing the fired heater duty, which eventually increases the total operating cost of the column. The total annualised cost of the new column structure is $8.47 \$ \mathrm{MM} \mathrm{y}^{-1}$. 
Table 3a CDU operating conditions (Case 2)

\begin{tabular}{lcc}
\hline Variable & Initial value & Case 2 \\
\hline PA 1 duty $(\mathrm{MW})$ & 11.2 & 9.58 \\
PA 2 duty $(\mathrm{MW})$ & 17.89 & 16.19 \\
PA 3 duty $(\mathrm{MW})$ & 12.84 & 15.20 \\
PA 1 DT $\left({ }^{\circ} \mathrm{C}\right)$ & 20 & 21 \\
PA 2 DT $\left({ }^{\circ} \mathrm{C}\right)$ & 50 & 43 \\
PA 3 DT $\left({ }^{\circ} \mathrm{C}\right)$ & 30 & 21 \\
Main steam $\left(\mathrm{kmol} \mathrm{h}{ }^{-1}\right)$ & 1200 & 900 \\
HD steam $\left(\mathrm{kmol} \mathrm{h}{ }^{-1}\right)$ & 250 & 188 \\
Feed temperature $\left({ }^{\circ} \mathrm{C}\right)$ & 365 & 361 \\
Reflux ratio & 4.17 & 3.39 \\
\hline
\end{tabular}

Table 3b Product quality and flow rate (Case 2)

\begin{tabular}{c|cc|cc|cc}
\hline Products & \multicolumn{2}{|c|}{ T5\% $\left({ }^{\circ} \mathrm{C}\right.$, ASTM D86) } & \multicolumn{2}{|c|}{ T95\% $\left({ }^{\circ} \mathrm{C}, \mathrm{ASTM}\right.$ D86) } & \multicolumn{2}{c}{ Flow rates $\left(\mathrm{m}^{3} \mathrm{~h}^{-1}\right)$} \\
\hline & Initial value & Case 2 & Initial value & Case 2 & Initial value & Case 2 \\
\hline LN & 25.9 & 24 & 110.6 & 111 & 103.5 & 99.9 \\
$\mathrm{HN}$ & 138.9 & 131 & 186.6 & 187 & 78.2 & 80.8 \\
$\mathrm{LD}$ & 215.9 & 213 & 301.5 & 301 & 140.3 & 135.1 \\
$\mathrm{HD}$ & 310.7 & 300 & 354.4 & 354 & 48.1 & 54.3 \\
RES & 361.4 & 361 & 754.3 & 754 & 292.5 & 292.5 \\
\hline
\end{tabular}


Table 3c Utility demand and column cost (Case 2)

\begin{tabular}{lccc}
\hline Variable & Initial value & Case 2 & Units* \\
\hline Utility requirements & & & \\
Hot utility & 54.61 & 44.32 & $\mathrm{MW}$ \\
Cold utility & 61.18 & 45.90 & $\mathrm{MW}$ \\
Cost analysis & & & \\
Utility cost & 8.51 & 6.89 & $\$ \mathrm{MM} \mathrm{y}^{-1}$ \\
Steam cost & 1.77 & 1.33 & $\$ \mathrm{MM} \mathrm{y}^{-1}$ \\
& & & \\
Total operating cost & 10.28 & 8.22 & $\$ \mathrm{MM} \mathrm{y}^{-1}$ \\
Annualised capital cost & 0.33 & 0.26 & $\$ M M \mathrm{y}^{-1}$ \\
Total annualised cost & $\mathbf{1 0 . 6 1}$ & $\mathbf{8 . 4 7}$ & $\mathbf{\$ M M ~ y}$ \\
\hline
\end{tabular}

In Table 3b, the flow rate of the atmospheric residue (RES) remains unchanged, compared to the initial values. Therefore, no valuable product is lost from the atmospheric crude oil distillation unit. Furthermore, all of the product ASTM boiling temperatures are within $10{ }^{\circ} \mathrm{C}$ of the specified values; again, no constraints on product quality are violated.

\section{Conclusions}

The design of a crude oil distillation unit is a nontrivial task due to the large number of degrees of freedom and complex interactions between individual units. Further challenges arise due to the need to design the complex column and heat recovery system simultaneously. Modified shortcut column models based on Fenske-Underwood-Gilliland have been applied for these purposes. However, the accuracy of these models can be low and they cannot be readily applied to any column configuration.

This article introduced a simulation-optimization framework for the design of crude oil distillation units that overcomes existing limitations, where maximum heat recovery is considered using pinch analysis. The approach presented combines a rigorous tray-by-tray model of a complex crude oil distillation unit implemented in Aspen HYSYS v8.6 with a genetic algorithm coded in Matlab R2015a. The optimization of the superstructure of the crude oil distillation column naturally leads to an MINLP model. This MINLP, solved by a GA, optimizes the crude oil distillation unit configuration (i.e. feed tray location, pumparound and side-stripper locations, number of trays in each section of the column) along with 
its operating conditions (i.e. feed inlet temperature, pump-around duties and temperature drops, stripping steam flow rates and reflux ratio) simultaneously.

One important advantage of using stochastic optimizers is that they do not require derivatives and are designed to avoid getting trapped in locally optimal solutions (although they cannot guarantee global optimality within a given tolerance). Computational results for the case study demonstrate that the proposed framework is capable of identifying designs that significantly improve the starting solution. In addition, it was shown that product quality specifications can be met effectively using a suitable penalty function, although this may be at the expense of some valuable products slipping into the residue stream. This limitation can be overcome by constraining flow rates within allowable limits.

Future work will explore the use of surrogate models ${ }^{48-51}$ of the distillation column in the optimization. Furthermore, to capture trade-offs between HEN capital cost and other costs, the framework needs to be extended to account for the synthesis of the heat exchanger network. Lastly, the proposed framework will be extended to retrofit of the complex crude oil distillation unit.

\section{Associated content \\ *S Supporting Information \\ Data on crude oil properties and characterization; initial feasible design data; and results for optimization of the crude oil distillation unit presented in the case study. This information is available free of charge via the Internet at http:// pubs.acs.org/.}

\section{Author information}

\section{Corresponding Author}

*E-mail: dauda.ibrahim@manchester.ac.uk

Notes

The authors declare no competing financial interest. 


\section{Acknowledgement}

The authors would like to acknowledge the financial support from Petroleum Technology Development Fund (PTDF), Nigeria, for sponsoring this PhD research.

\section{References}

(1) Liebmann, K.; Dhole, V.R.; Jobson, M. Integrated Design of a Conventional Crude Oil Distillation Tower Using Pinch Analysis. Chem. Eng. Res. Des. 1998, 76 (3), 335-347.

(2) Szklo, A.; Schaeffer, R. Fuel Specification, Energy Consumption and $\mathrm{CO}_{2}$ Emission in Oil Refineries. Energy 2007, 32 (7), 1075-1092.

(3) Gary, J.H.; Handwerk, G.E. Petroleum Refining: Technology and Economics (4 ${ }^{\text {th }}$ ed); Marvel Dekker: New York, 2001.

(4) Nelson, W.L. Petroleum Refinery Engineering; McGraw-Hill: New York, 1958.

(5) Watkins, R.N. Petroleum Refinery Distillation; Gulf Publishing Company, Book Division: Texas, 1979.

(6) Jones, D.S.J. Elements of Petroleum Processing; John Wiley \& Sons: West Sussex, UK, 1995.

(7) Suphanit, B. Design of Complex Distillation System, PhD Thesis, UMIST, Manchester, UK., 1999.

(8) Rastogi, V. Heat Integrated Crude Oil Distillation System Design., University of Manchester, UK., 2006.

(9) Chen, L. Heat-Integrated Crude Oil Distillation System Design. PhD Thesis, Univ. Manchester, UK. 2008.

(10) Caballero, J.A.; Milan-Yanez, D.; Grossmann, I.E. Rigorous Design of Distillation Columns: Integration of Disjunctive Programming and Process Simulators. Ind. Eng. Chem. Res. 2005, 44 (17), 6760-6775.

(11) Brunet, R.; Cortés, D.; Guillén-Gosálbez, G.; Jiménez, L.; Boer, D. Minimization of the LCA Impact of Thermodynamic Cycles Using a Combined SimulationOptimization Approach. Appl. Therm. Eng. 2012, 48, 367-377.

(12) Brunet, R.; Guillen-Gosalbez, G.; Perez-Correa, J.R.; Caballero, J.A.; Jimenez, L. Hybrid Simulation-Optimization Based Approach for the Optimal Design of Single- 
Product Biotechnological Processes. Comput. Chem. Eng. 2012, 37, 125-135.

(13) Morandin, M. Pinch Analysis cascade calculation, 2014.

http://uk.mathworks.com/matlabcentral/fileexchange/47743-cascade-m (accessed Nov 20, 2014).

(14) Liebmann, K. Integrated Crude Oil Distillation Design., PhD Thesis, UMIST, Manchester, UK. 1996.

(15) Sharma, R.; Jindal, A.; Mandawala, D.; Jana, S.K. Design/Retrofit Targets of PumpAround Refluxes for Better Energy Integration of a Crude Distillation Column. Ind. Eng. Chem. Res. 1999, 38 (6), 2411-2417.

(16) Dhole, V.R.; Buckingham, P.R. Refinery Column Integration for Debottlenecking and Energy Saving. Proc. ESCAPE IV Conf. Dublin 1994.

(17) Bagajewicz, M.; Ji, S. Rigorous Procedure for the Design of Conventional Atmospheric Crude Fractionation Units. Part I: Targeting. Ind. Eng. Chem. Res. 2001, 40, 617-626.

(18) Grossmann, I.E.; Caballero, J.A.; Yeomans, H. Advances in Mathematical Programming for Automated Design, Integration and Operation of Chemical Processes. Korean J. Chem. Eng. 1999, 16, 407-426.

(19) Grossmann, I.E.; Guillén-Gosálbez, G. Scope for the Application of Mathematical Programming Techniques in the Synthesis and Planning of Sustainable Processes. Comput. Chem. Eng. 2010, 34 (9), 1365-1376.

(20) Dowling, A.W.; Biegler, L.T. A Framework for Efficient Large Scale EquationOriented Flowsheet Optimization. Comput. Chem. Eng. 2015, 72, 3-20.

(21) Skiborowski, M.; Rautenberg, M.; Marquardt, W. A Hybrid EvolutionaryDeterministic Optimization Approach for Conceptual Design. Ind. Eng. Chem. Res. 2015, 54 (41), 10054-10072.

(22) Steimel, J.; Engell, S. Optimization-Based Support for Process Design under Uncertainty: A Case Study. AIChE 2016, 62 (9), 3404-3419.

(23) Corbetta, M.; Grossmann, I.E.; Manenti, F. Process Simulator-Based Optimization of Biorefinery Downstream Processes under the Generalized Disjunctive Programming Framework. Comput. Chem. Eng. 2016, 88, 73-85. 
(24) Javaloyes-Antón, J.; Ruiz-Femenia, R.; Caballero, J.A. Rigorous Design of Complex Distillation Columns Using Process Simulators and the Particle Swarm Optimization Algorithm. Ind. Eng. Chem. Res. 2013, 52 (44), 15621-15634.

(25) Towler, G.P. and Sinnott, R.K. Chemical Engineering Design: Principles, Practice and Economics of Plant and Process Design (2nd ed); Butterworth-Heineman: Oxford, 2013.

(26) Yee, T.F.; Grossmann, I.E. Simultaneous Optimization Models for Heat Integration II. Heat-Exchanger Network Synthesis. Comput. Chem. Eng. 1990, 14 (10), 11651184.

(27) Seader, J.D.; Henley, E.J.; Roper, D.K. Separation Process Principles, 3rd Edition; John Wiley \& Sons: New York, 2010.

(28) Yeomans, H.; Grossmann, I.E. Optimal Design of Complex Distillation Columns Using Rigorous Tray-by-Tray Disjunctive Programming Models. Ind. Eng. Chem. Res. 2000, 39 (11), 4326-4335.

(29) Smith, R. Chemical Process: Design and Integration; Wiley: Chichester,UK. 2005.

(30) Guthrie, K.M. Data and Techniques for Preliminary Capital Cost Estimating. Chem. Eng. 1969, March, 114-142.

(31) Economic Indicators 2012. www.che.com (accessed Nov 20, 2014).

(32) Economic Indicators 2014. www.che.com (accessed Nov 20, 2014).

(33) Stichlmair, J.; Fair, J.R. Distillation: Principles and Practices; Wiley-VCH: New York, 1998.

(34) Kister, H. Distillation Design; McGraw-Hill Education: New York, 1992.

(35) Branan, C. R. Rules of Thumb for Chemical Engineers; Gulf Professional Publishing: Texas, 2005.

(36) Edgar, T.F.; Himmelblau, D.M.; Lasdon, L.S. Optimization of Chemical Processes; McGraw-Hill: New York, 2001.

(37) Floudas, C.A. Deterministic Global Optimization: Theory, Methods and Applications; Nonconvex Optimization and Its Applications; Springer US, 2013.

(38) Biegler, L.T.; Grossmann, I.E.; Westerberg, A.W. Systematic Methods of Chemical 
Process Design; Prentice Hall PTR: New Jersey, 1997.

(39) Duran, M.A.; Grossmann, I.E. An Outer-Approximation Algorithm for a Class of Mixed-Integer Nonlinear Programs. Math. Program. 1986, 36 (3), 307-339.

(40) Heyman, D.P.; Sobel, M.J. Stochastic Models in Operations Research: Stochastic Optimization; Dover Publications: New York, 2003.

(41) Floudas, C.A. Nonlinear and Mixed-Integer Optimization: Fundamentals and Applications; Topics in Chemical Engineering; Oxford University Press, 1995.

(42) Odjo, A.O.; Sammons Jr, N.E.; Yuan, W.; Marcilla, A.; Eden, M.R.; Caballero, J.A. Disjunctive-Genetic Programming Approach to Synthesis of Process Networks. Ind. Eng. Chem. Res. 2011, 50 (10), 6213-6228.

(43) Fiandaca, G.; Fraga, E.S. A Multi-Objective Genetic Algorithm for the Design of Pressure Swing Adsorption. Eng. Optim. 2009, 10, 1-24.

(44) Vazquez-Castillo, J.A.; Venegas-Sánchez, J.A.; Segovia-Hernández, J.G.; HernándezEscoto, H.; Hernández, S.; Gutiérrez-Antonio, C.; Briones-Ramírez, A. Design and Optimization, Using Genetic Algorithms, of Intensified Distillation Systems for a Class of Quaternary Mixtures. Comput. Chem. Eng. 2009, 33 (11), 1841-1850.

(45) Lee, E.S.Q.; Rangaiah, G.P. Optimization of Recovery Processes for Multiple Economic and Environmental Objectives. Ind. Eng. Chem. Res. 2009, 48 (16), 76627681.

(46) Deep, K.; Singh, K.P.; Kansal, M.L.; Mohan, C. A Real Coded Genetic Algorithm for Solving Integer and Mixed Integer Optimization Problems. Appl. Math. Comput. 2009, $212(2), 505-518$.

(47) Mitchell, M. An Introduction to Genetic Algorithms; MIT Press, Cambridge, US. 1998, $1-40$.

(48) Ochoa-Estopier, L.M.; Jobson, M.; Smith, R. Operational Optimization of Crude Oil Distillation Systems Using Artificial Neural Networks. Comput. Chem. Eng. 2013, 59, $178-185$.

(49) Ochoa-Estopier, L.M.; Jobson, M. Optimization of Heat-Integrated Crude Oil Distillation Systems. Part I: The Distillation Model. Ind. Eng. Chem. Res. 2015, 54 (18), 4988-5000. 
1

2

3

4

5

6

7

8

9

10

11

12

13

14

15

16

17

18

19

20

21

22

23

24

25

26

27

28

29

30

31

32

33

34

35

36

37

38

39

40

41

42

43

44

45

46

47

48

49

50

51

52

53

54

55

56

57

58

59

60

(50) Quirante, N.; Javaloyes, J.; Caballero, J.A. Rigorous Design of Distillation Columns Using Surrogate Models Based on Kriging Interpolation. AIChE 2015, 61 (7), 21692187.

(51) López C., D.C.; Hoyos, L.J.; Mahecha, C.A.; Arellano-Garcia, H.; Wozny, G. Optimization Model of Crude Oil Distillation Units for Optimal Crude Oil Blending and Operating Conditions. Ind. Eng. Chem. Res. 2013, 52 (36), 12993-13005. 


\section{Table of contents (TOC) graphic}

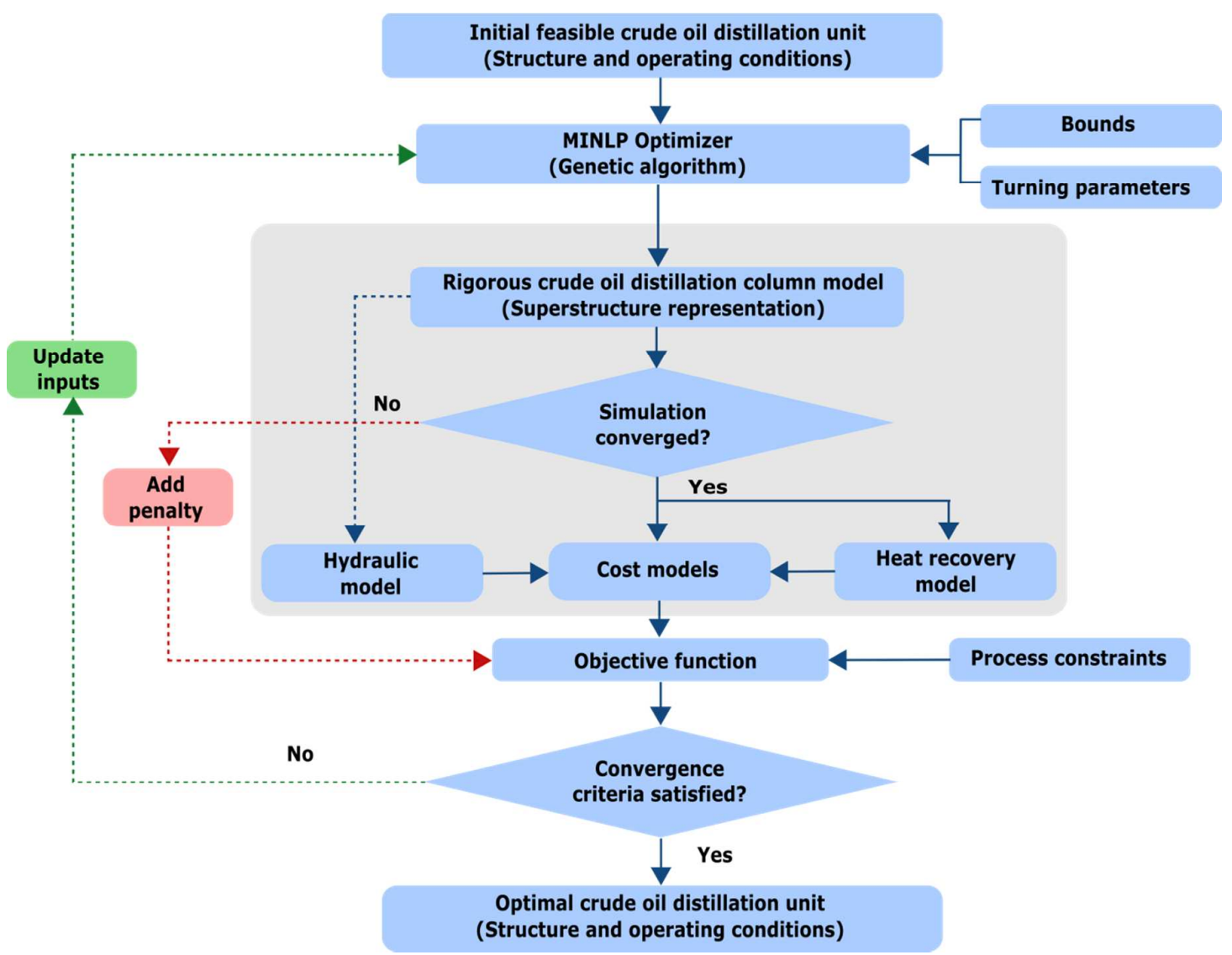

